\title{
Synthesis, Mass Spectra Investigation and Biological Activity of Some Pyrimidine Derivatives
}

\author{
Mohamed Abd El-Moneim \\ Chemistry Department, Faculty of Science, Port-Said University, Port-Said, Egypt
}

\begin{abstract}
Disubstituted-5-cyano-4-hydroxypyrimidines (3 and 4) have been prepared via cyclocondensation of ethyl- $\beta$-(3-bromo-4-methoxy phenyl)- $\alpha$-cyanoacrylate (2) with guanidine hydrochloride and thiourea in presence of anhydrous potassium carbonate. Treatment of 3 with acetic anhydride, ethyl chloroacetate, methyl acrylate and 4-methylphenacyl bromide afforded the corresponding $N$-acetyl (6), $N$-alkyl (9) and fused pyrimidines $(7,8)$. The electron impact (EI) ionization mass spectral fragmentations of some synthesized compounds are discussed. Some of the synthesized compounds were tested for their antimicrobial and inhibitory activities against Breast carcinoma cells (MCF-7) cell line.
\end{abstract}

\section{Introduction}

Because of their interesting biological activities, low molecular weight heteroycles have attracted enormous attention in medicinal chemistry. Nitrogen-containing heterocycles have recently received a significant importance because of their diverse pharmacological properties [1-5]. Of these heterocycles, the synthesis, reactions and biological activities of pyrimidine containing molecules stands as an ever expanding area of research in hetero aromatic chemistry. However, the synthesis of some substituted pyrimidines by the treatment of $\alpha, \beta$-unsaturated esters with thiourea and guanidine in the presence of anhydrous potassium carbonate were reported [6]. The literature indicated that compounds having pyrimidine nucleus possesses broad range of biological activity like anticancer, antiviral, anti-HIV, antibacterial, antihypertensive, anticonvulsant, antithyroid, and antibiotics [7].The electron Impact (EI) ionization mass spectral fragmentation of some of the synthesized 2-aminopyrimidine and 2-mercaptopyrimidine derivatives were described.

\section{1) Chemistry}

\section{Results and Discussion}

Condensation of 3-bromo-4-methoxybenzaldehyde (1) with ethylcyanoacetate in the presence of anhydrous potassium carbonate led to the formation of ethyl $\beta$-(3-bromo-4-methoxyphenyl)- $\alpha$-cyanoacrylate (2). The reaction of ester derivative (2) with guanidine hydrochloride and thiourea in methanol in presence of anhydrous potassium carbonate under reflux, yielded the corresponding 6-(3-bromo-4-methoxyphenyl)-5-cyano4-hydroxy-2-aminopyrimidine and 6-(3-bromo-4-methoxyphenyl)-5-cyano-4-hydroxy-2mercaptopyrimidine (4, Scheme 1$)$.

Treatment of 2-mercaptopyrimidine (4) with 4-methylphenacyl bromide in presence of fused sodium acetate in acetic acid under reflux afforded the corresponding 6-(3-bromo-4-methoxyphenyl)-5-cyano-4-oxo-3(p-methylphenyl)-thiazolo[2,3-b]pyrimidine (5; Scheme 1).

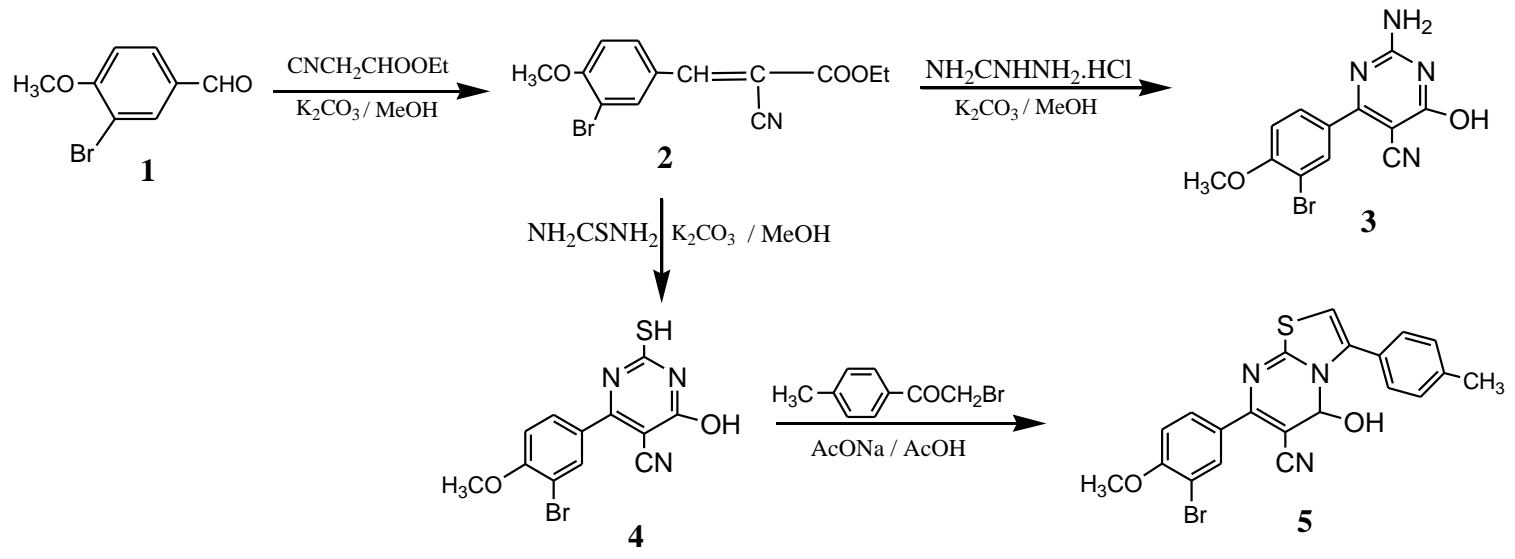

Scheme 1 
Acetylation of 2-aminopyrimidine (3) with acetic anhydride under reflux led to the formation of 6-(3-bromo-4methoxyphenyl)5-cyano-4-hydroxy-2-(acetylamino)pyrimidine (6). Treatment of 2-aminopyrimidine (3) with ethylchloroacetate in acetic acid afforded the corresponding 6-hydroxy-5-cyano-4-imidazolidino[2,1-b]

pyrimidin-3-one (7). The reaction of methyl acrylate in dimethylformamide in presence of fused sodium acetate gave the corresponding 5-(3-bromo-4-methoxyphenyl)-6-cyano-7-hydroxy-2,3-dihydropyrimidino[2,1-

b]pyrimidin-4-one (8). Alkylation of 2-aminopyrimidine (3) with 4-methylphenacylbromide in acetic acid under reflux yielded the corresponding 2-( $p$-methylbenzoyl)methylamino-4-hydroxy-5-cyano-6-(3-bromo-4methoxyphenyl)pyrimidine (9, Scheme 2$)$.

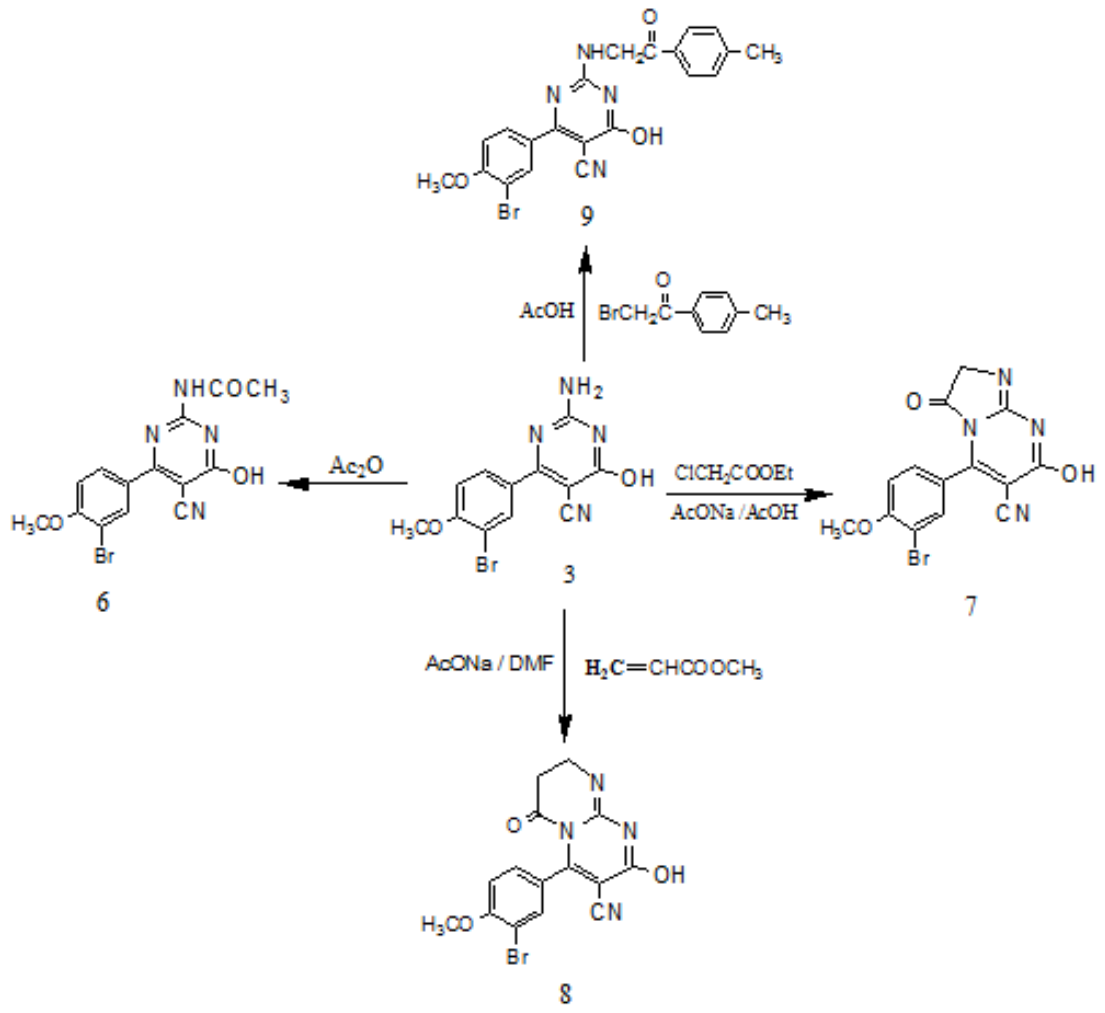

Scheme 2

2) Mass Spectrometry

The mass spectral decomposition modes [6-10] of the prepared 2-mercaptopyrimidine and 2aminopyrimidine derivatives have been investigated. Table 1 lists the $\mathrm{m} / \mathrm{z}$ (relative abundance, \%) values of the principle fragment of synthesized compounds, while figures 1,2,3,4,5 and 6 illustrated the mass spectra of compounds $3,4,5,6,8$ and 9 respectively.

\section{Compound 3}

The mass spectrum of compound 3 (Fig.1) showed the molecular ion peaks at $\mathrm{m} / \mathrm{z} 320 / 322$ corresponding to the molecular formula $\mathrm{C}_{12} \mathrm{H}_{9} \mathrm{~N}_{4} \mathrm{BrO}_{2}$. The base peaks of compounds 3 was found at $\mathrm{m} / \mathrm{z} 322$ $(\mathrm{M}+2)$ along with the molecular ion peak due to the presence of isotope of bromine atom present in this compounds. The molecular ion of compound 3 fragmented further and involved two pathways as illustrated in table 1 (Scheme 3). The molecular ion of $\mathrm{m} / \mathrm{z} 320$ fragmented via pathway A to give peak at $\mathrm{m} / \mathrm{z} 279$ by losing $\mathrm{NH}-\mathrm{CN}$ group. The peak at $\mathrm{m} / \mathrm{z} 279$ underwent fragmentation to produce a peak at $\mathrm{m} / \mathrm{z} 212$. It further underwent loss of $\mathrm{NH}, \mathrm{HBr}, \mathrm{C}_{2}$ and $\mathrm{CH}_{2} \mathrm{O}$ to give peaks at m/z 197, 117, 93 and m/z 63 respectively. Accordingly, the same molecular ion of $\mathrm{m} / \mathrm{z} 320$ fragmented via the pathway B by the cleavage of isocyanate group (NCO) to give peak at $\mathrm{m} / \mathrm{z} 278$, which lose $\mathrm{NH}-\mathrm{CN}$ group to give a peak at $\mathrm{m} / \mathrm{z} 237$. Then lose of formaldehyde and bromine atom to a peak at $\mathrm{m} / \mathrm{z} 128$. It further underwent loss of $\mathrm{CH}=\mathrm{CHN}$ molecule to give a peak at $\mathrm{m} / \mathrm{z} 76$.

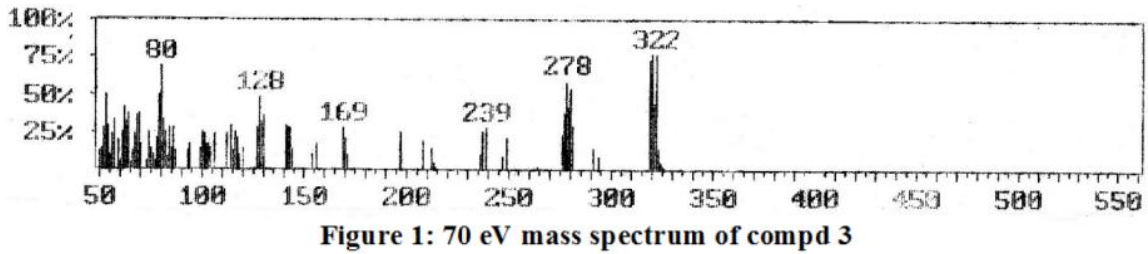




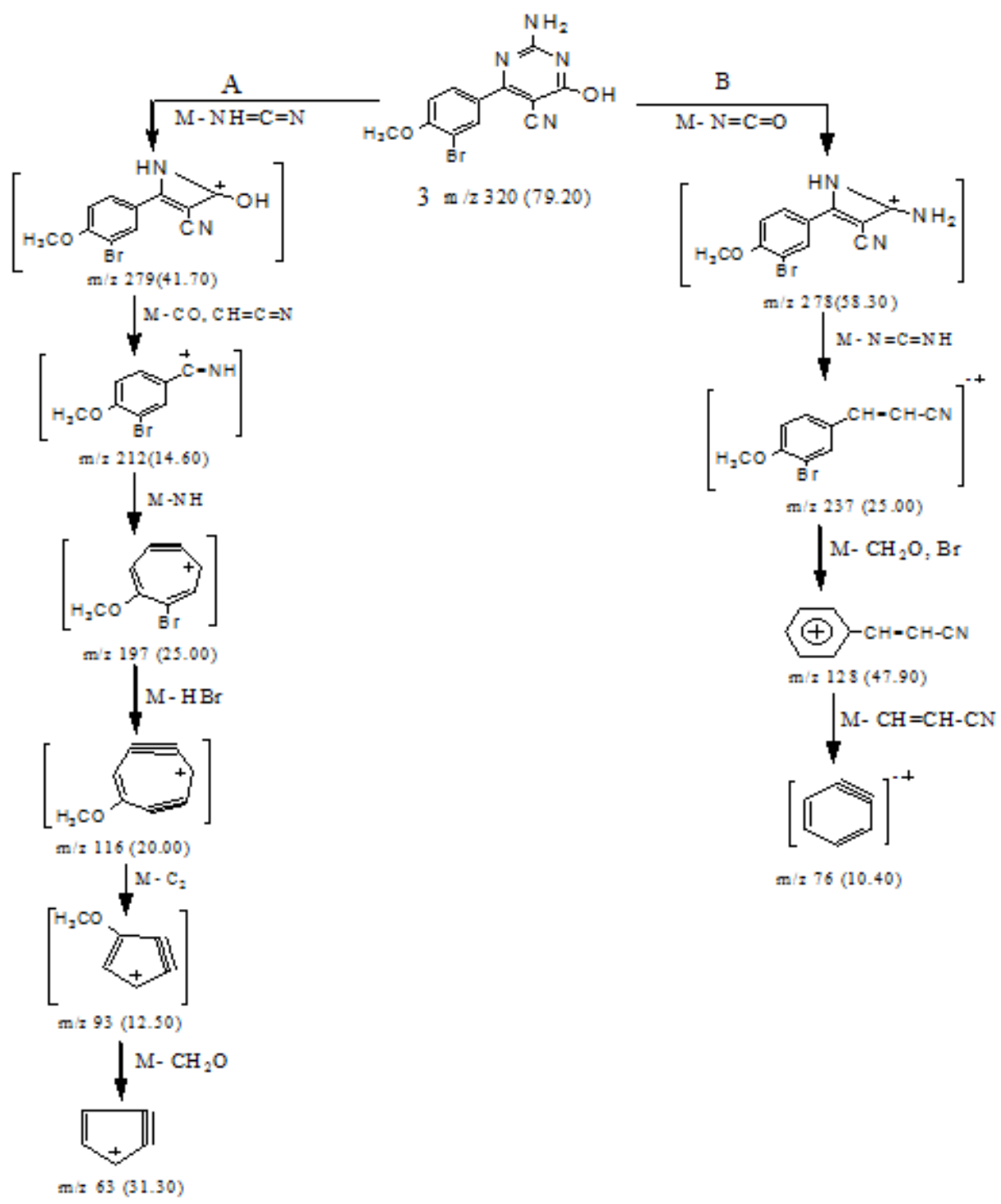

Scheme 3:Main fragmentation pathway of compd.3

\section{Compound 4:}

The mass spectrum of compound 4 (Fig. 2) showed the molecular ion peak at $\mathrm{m} / \mathrm{z} 337 / 339$ corresponding to the molecular formula $\mathrm{C}_{12} \mathrm{H}_{8} \mathrm{~N}_{3} \mathrm{BrO}_{2}$. The base peak of compounds 4 was found at $339(\mathrm{M}+2)$. From the study of mass spectra of compound 4 , it had fragmented to the ion of $\mathrm{m} / \mathrm{z} 256$ via the pathway A. The ion of $\mathrm{m} / \mathrm{z} 256$ underwent fragmentation to produce a peak at $\mathrm{m} / \mathrm{z} 211$ by losing thioformyl group (CHS). The ion at $\mathrm{m} / \mathrm{z} 211$ underwent loss of $\mathrm{CN}, \mathrm{OCH}_{3}, \mathrm{Br}$ and $\mathrm{C}_{2}$ to give peaks at $\mathrm{m} / \mathrm{z} 185,154,75$ and 51 respectively. The molecular ion of compound 4 was also found to undergo fragmentation via the pathway B to produce the ion of $\mathrm{m} / \mathrm{z} 278$. The ion of $\mathrm{m} / \mathrm{z} 278$ broked to gave an ion at $\mathrm{m} / \mathrm{z} 236$ which lose isocyanate group (NCO). The ion at $\mathrm{m} / \mathrm{z} 236$ fragmented to gsve an ion at $\mathrm{m} / \mathrm{z} 210$ which lose cyano group $(\mathrm{CN})$. Also the ion at $\mathrm{m} / \mathrm{z} 210$ underwent loss of hydrogen bromide, formaldehyde and acetylene molecules to give peaks at $\mathrm{m} / \mathrm{z} \mathrm{130,100}$ and $\mathrm{m} / \mathrm{z} 74$ respectively (Scheme 4).

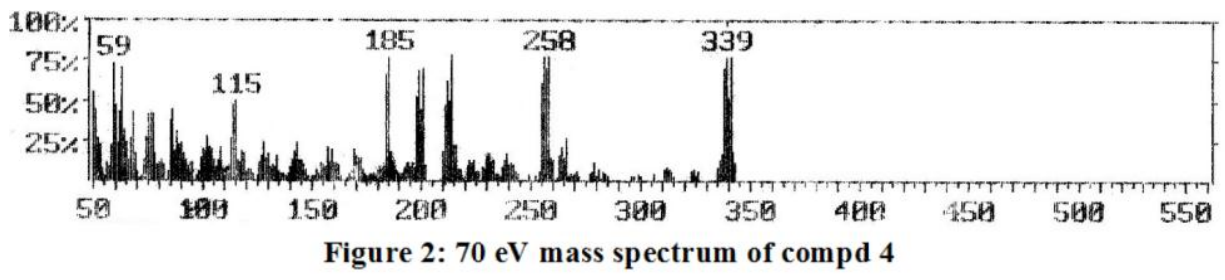




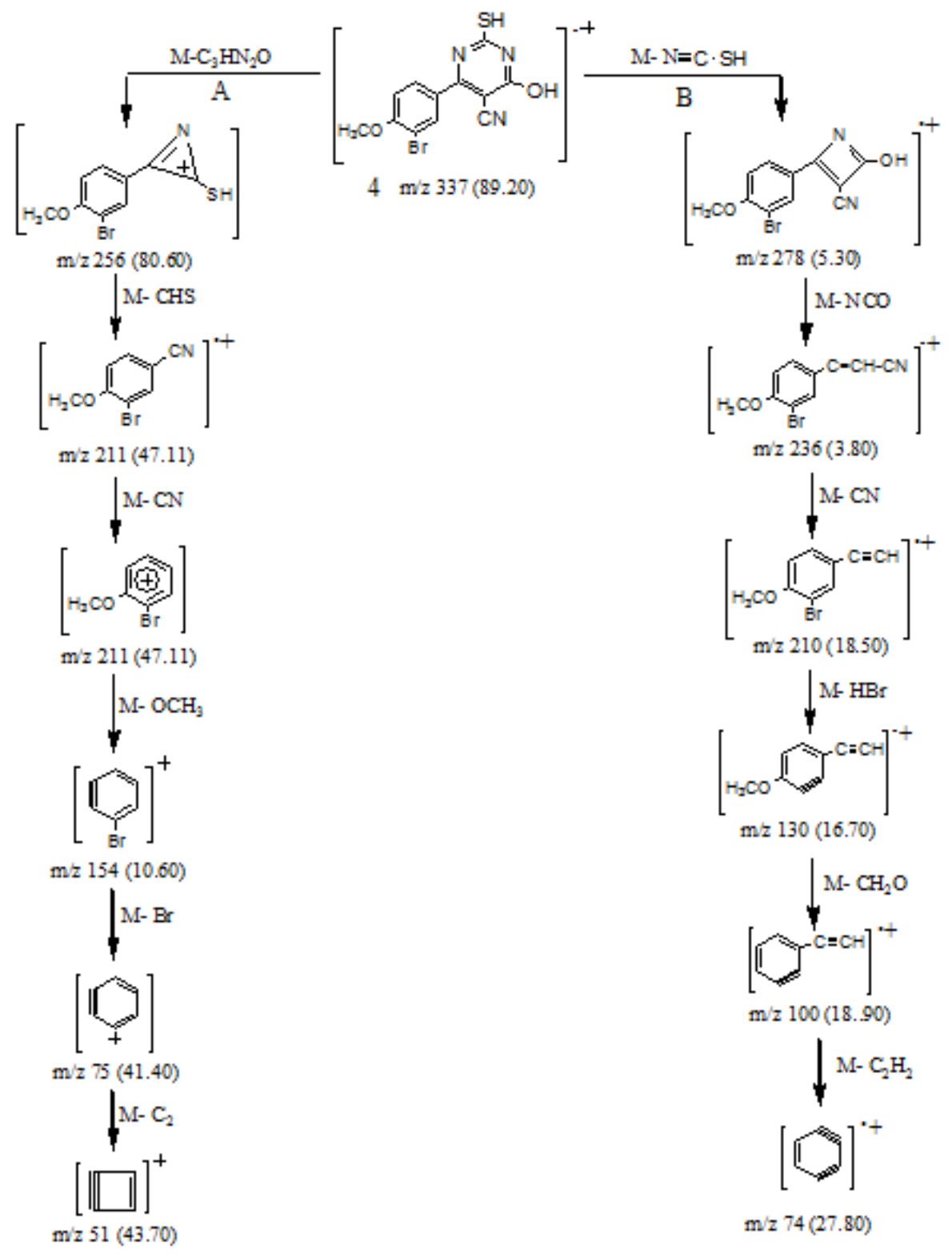

Scheme 4:Main fragmentation pathway of compd.4

\section{Compound 5:}

From the mass spectrum of compound 5 (Fig.3), it was concluded that the molecular ion at $\mathrm{m} / \mathrm{z} 451 / 453$. The ion of $\mathrm{m} / \mathrm{z} 451$ underwent fragmentation via the pathway A to give a peak at $\mathrm{m} / \mathrm{z} 263$. The ion at $\mathrm{m} / \mathrm{z} 263$ broke to give stable fragment at $\mathrm{m} / \mathrm{z} 185$. The base ion of $\mathrm{m} / \mathrm{z} 185$ underwent loss of methyl group $\left(\mathrm{CH}_{3}\right)$, carbon monoxide $(\mathrm{CO})$ and bromine atom to give peaks at $\mathrm{m} / \mathrm{z} 170,142 \mathrm{and} \mathrm{m} / \mathrm{z}$ 63. Also, the same molecular ion peak at $\mathrm{m} / \mathrm{z} 451$ undergo fragmentation via the pathway B to produce the ion of $\mathrm{m} / \mathrm{z} 188$, which lose $(\mathrm{N}=\mathrm{C}=\mathrm{N})$ group to give the ion of $\mathrm{m} / \mathrm{z} 148$. The ion at $\mathrm{m} / \mathrm{z} 148$ underwent loss of sulphur atom (S), methyl group $\left(\mathrm{CH}_{3}\right)$ and acetylene molecule to give peaks at m/z 116, 101 and 75 respectively (Scheme 5).

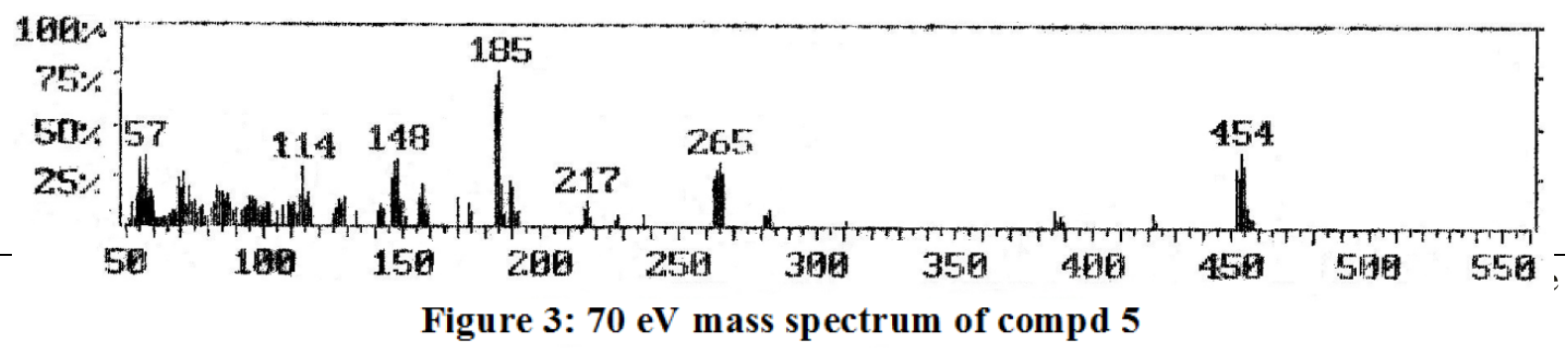




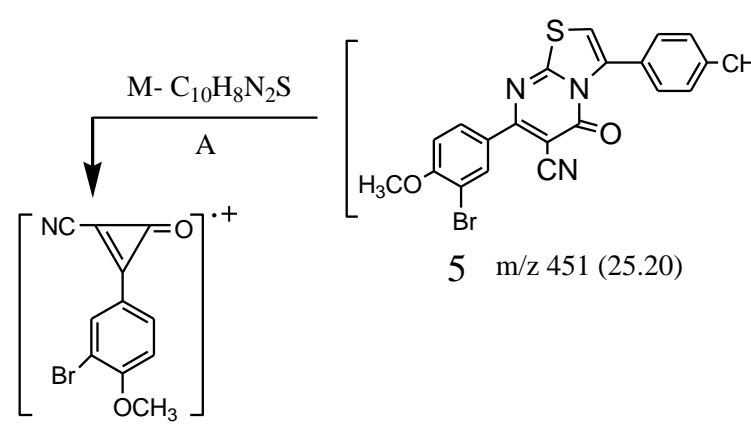

$\mathrm{m} / \mathrm{z} 263$ (23.20)
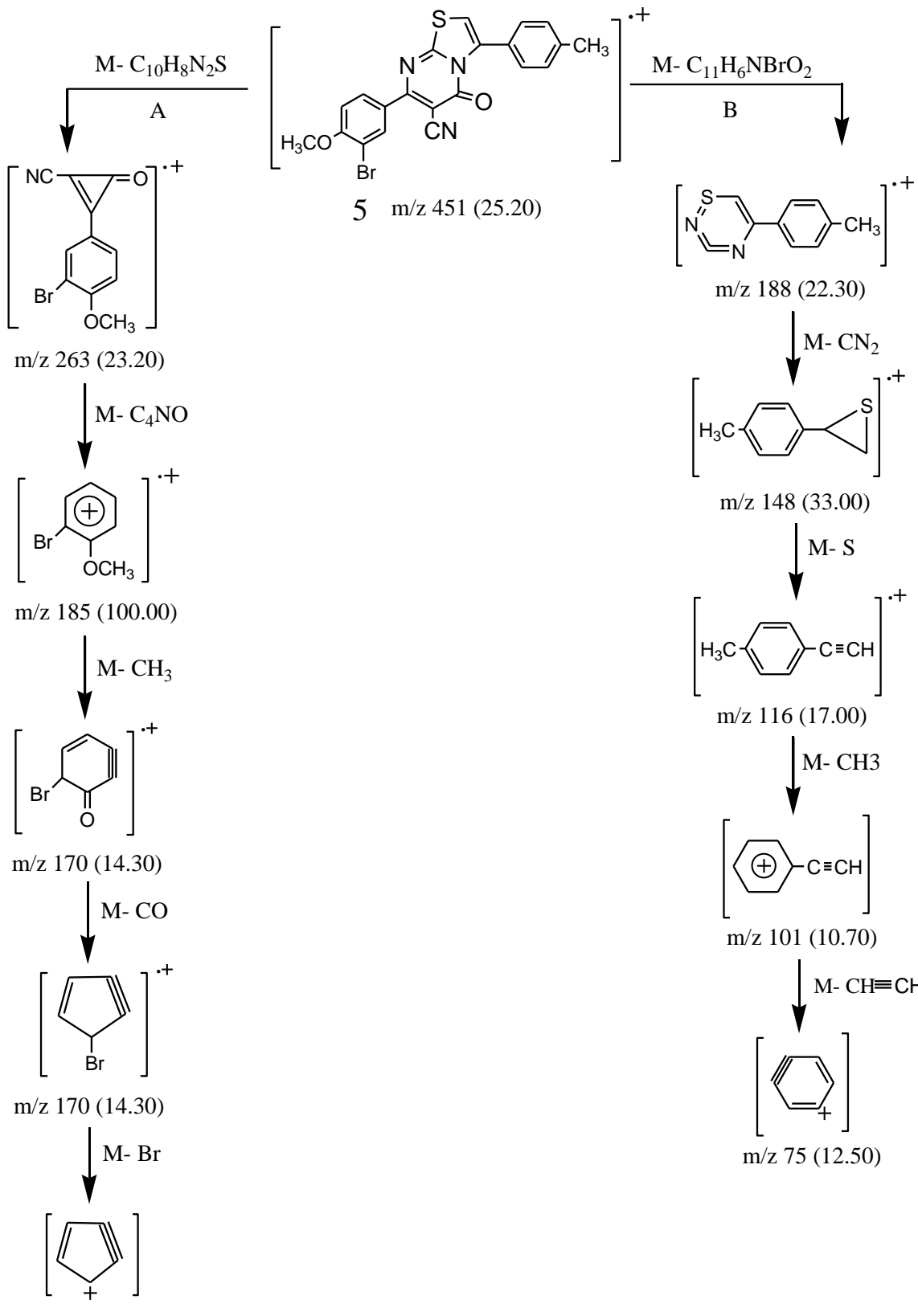

$\mathrm{m} / \mathrm{z} 188$ (22.30)

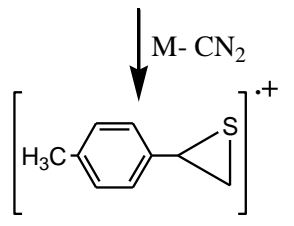

$\mathrm{m} / \mathrm{z} 148$ (33.00)
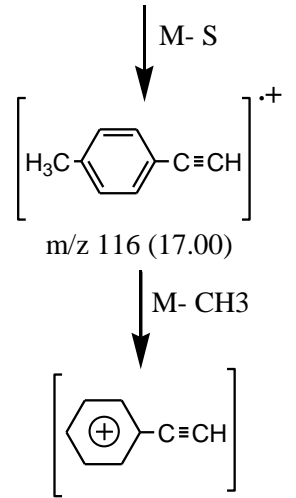

$\mathrm{m} / \mathrm{z} 101(10.70)$

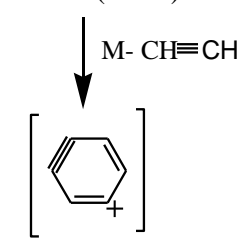

$\mathrm{m} / \mathrm{z} 75(12.50)$

$\mathrm{m} / \mathrm{z} 63$ (2.70)

Scheme 5: Main fragmentation pathway of compd.5

\section{Compound 6, 8 and 9:}

The mass spectra of compounds 6 (Fig. 4), 8 (Fig. 5) and 9 (Fig. 6) shows relatively small molecular ions peaks typical of a cleavage and rearrangement processes type fragmentation. From the study of the mass spectra of compounds 6,8 and 9, it was found that the molecular ion for all these compounds fragmented further and involved two various pathways as illustrated by Table 1 .

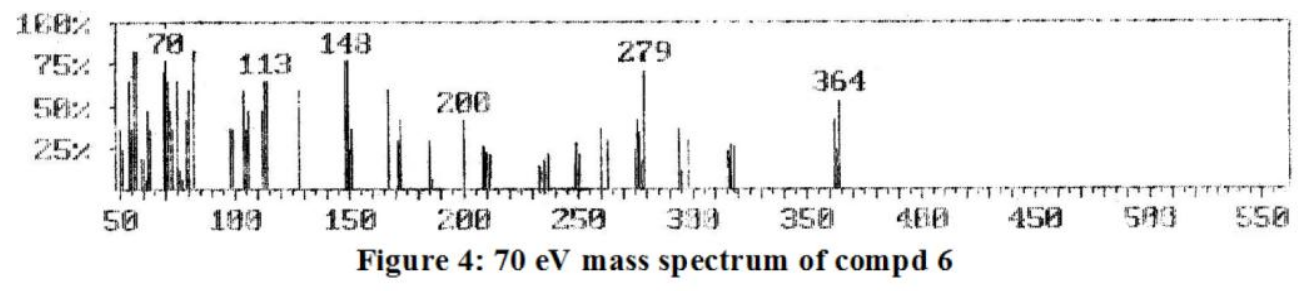




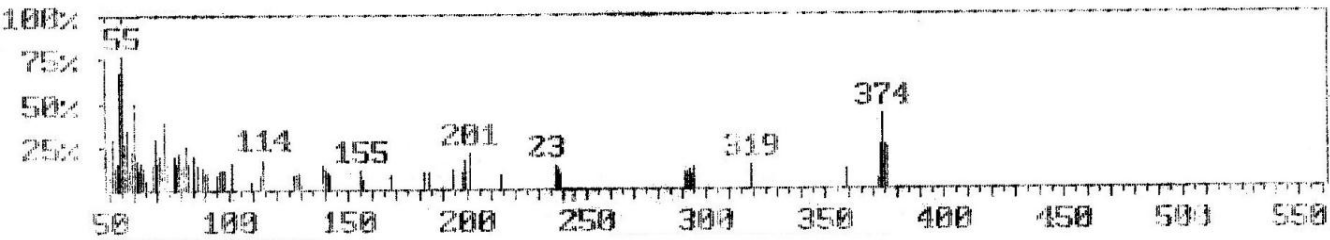

Figure 5: $70 \mathrm{eV}$ mass spectrum of compd 8

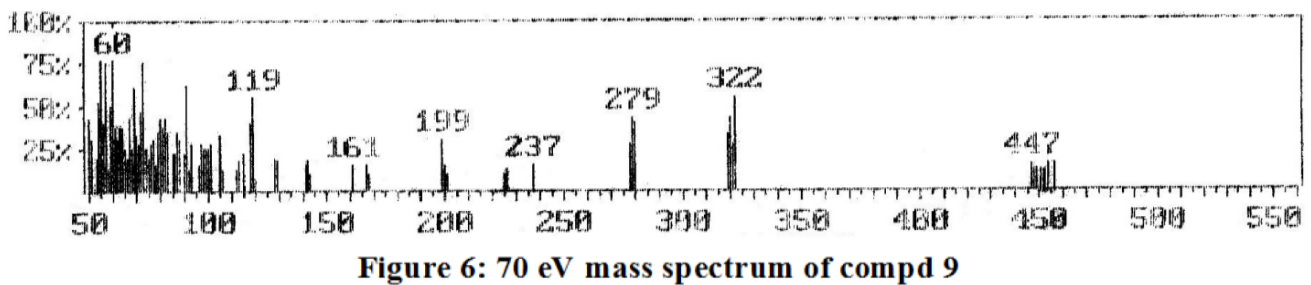

Table 1: EI mass spectra (70eV) of compounds $1-6,8$ and $9 \mathrm{~m} / \mathrm{z}$ (relative intensity, \%)

\begin{tabular}{|c|c|c|c|c|c|c|}
\hline \multirow[t]{2}{*}{ Compd } & \multirow[t]{2}{*}{$\mathrm{M}^{+}$} & \multicolumn{2}{|c|}{ Pathway A } & \multicolumn{2}{|c|}{ Pathway B } & \multirow[t]{2}{*}{ Other Ions } \\
\hline & & $-\mathrm{M}$ & $\mathrm{m} / \mathrm{z}$ & $-\mathrm{M}$ & $\mathrm{m} / \mathrm{z}$ & \\
\hline 3 & $\begin{array}{c}{\left[\mathrm{C}_{12} \mathrm{H}_{9} \mathrm{~N}_{4} \mathrm{BrO}_{2}\right]^{+}} \\
320(79.20)\end{array}$ & $\begin{array}{c}\mathrm{NHCN} \\
\mathrm{CO}, \mathrm{C}_{2} \mathrm{HN} \\
\mathrm{NH} \\
\mathrm{HBr} \\
\mathrm{C}_{2} \\
\mathrm{CH}_{2} \mathrm{O}\end{array}$ & $\begin{array}{c}{\left[\mathrm{C}_{11} \mathrm{H}_{8} \mathrm{~N}_{2} \mathrm{BrO}_{2}\right]} \\
+ \\
279(41.70) \\
\\
{\left[\mathrm{C}_{8} \mathrm{H}_{7} \mathrm{NBrO}\right]^{+}} \\
212(14.60) \\
\\
{\left[\mathrm{C}_{8} \mathrm{H}_{6} \mathrm{NBrO}\right]^{+}} \\
197(25.00) \\
{\left[\mathrm{C}_{8} \mathrm{H}_{5} \mathrm{O}\right]^{+}} \\
117(20.80) \\
\\
{\left[\mathrm{C}_{6} \mathrm{H}_{5} \mathrm{O}\right]^{+}} \\
93(12.50) \\
\\
{\left[\mathrm{C}_{5} \mathrm{H}_{3}\right]^{+}} \\
63(31.30)\end{array}$ & $\begin{array}{c}\mathrm{CN}_{2} \mathrm{H} \\
\mathrm{Br}, \mathrm{CH}_{2} \mathrm{O} \\
\mathrm{C}_{3} \mathrm{H}_{2} \mathrm{~N}\end{array}$ & $\begin{array}{c}{\left[\mathrm{C}_{11} \mathrm{H}_{9} \mathrm{~N}_{3} \mathrm{BrO}\right]^{+}}_{278(58.30)} \\
\\
{\left[\mathrm{C}_{10} \mathrm{H}_{8} \mathrm{NBrO}\right]^{+}} \\
237(25.00) \\
\\
\left.\mathrm{C}_{9} \mathrm{H}_{6} \mathrm{~N}\right]^{+} \\
128(42.90) \\
\\
{\left[\mathrm{C}_{6} \mathrm{H}_{4}\right]^{+}} \\
76(10.40)\end{array}$ & $\begin{array}{c}322\left(\mathrm{M}^{+}+2,100\right), \\
\left.\text { 321( } \mathrm{M}^{+}+1,43.60\right), 319\left(\mathrm{M}^{+}-\right. \\
\text {1,72.92), 294(8.30), } \\
291(14.60), 281(29.50), \\
280(54.20), 277(37.50), \\
276(22.90), 249(20.80), \\
247(8.30), 239(27.10), \\
236(10.40), 214(2.10), \\
208(18.80), 171(10.40), \\
\text { 170(20.80), 169(27.10), } \\
\text { 156(16.70), 154(10.40), } \\
\text { 144(14.60), 143(.80), } \\
\text { 169(27.10), 156(16.70), } \\
\text { 154(10.40), 144(14.60), } \\
\text { 143(27.10), 142(27.10), } \\
\text { 141(29.20), 130(35.20), } \\
\text { 129(31.30), 127(27.10), } \\
\text { 118(10.40), 116(25.00), } \\
\text { 114(29.20), 112(22.90), } \\
\text { 106(22.90), 103(16.70), } \\
\text { 101(22.90), 100(25.00), } \\
\text { 93(12.50), 87(12.50), } \\
\text { 86(27.10), 80(68.80), } \\
\text { 79(50.00), 78(20.80), } \\
\text { 64(37.20), 53(50.00), } \\
52(27.10)\end{array}$ \\
\hline 4 & $\begin{array}{c}\left.\mathrm{C}_{12} \mathrm{H}_{8} \mathrm{~N}_{3} \mathrm{BrO}_{2} \mathrm{~S}\right]^{+} \\
337(89.20)\end{array}$ & $\begin{array}{c}\mathrm{C}_{3} \mathrm{HN}_{2} \mathrm{O} \\
\mathrm{CHS} \\
\mathrm{CN} \\
\mathrm{OCH}_{3} \\
\mathrm{Br} \\
\mathrm{C}_{2}\end{array}$ & $\begin{array}{c}{\left[\mathrm{C}_{9} \mathrm{H}_{7} \mathrm{~N}_{3} \mathrm{BrOS}\right]} \\
+ \\
256(80.60) \\
\\
{\left[\mathrm{C}_{8} \mathrm{H}_{6} \mathrm{NBrO}\right]^{+}} \\
211(47.11) \\
\\
{\left[\mathrm{C}_{7} \mathrm{H}_{6} \mathrm{~N}_{3} \mathrm{BrO}\right]^{+}} \\
185(84.60) \\
\\
{\left[\mathrm{C}_{6} \mathrm{H}_{3} \mathrm{Br}\right]^{+}} \\
154(10.60) \\
{\left[\mathrm{C}_{6} \mathrm{H}_{3}\right]^{+}} \\
75(41.40) \\
\\
{\left[\mathrm{C}_{6} \mathrm{H}_{3}\right]^{+}} \\
75(41.40)\end{array}$ & $\begin{array}{c}\mathrm{CHNS} \\
\mathrm{NCO} \\
\mathrm{CN} \\
\mathrm{HBr} \\
\mathrm{CH}_{2} \mathrm{O} \\
\mathrm{C}_{2} \mathrm{H}_{2}\end{array}$ & $\begin{array}{c}{\left[\mathrm{C}_{11} \mathrm{H}_{7} \mathrm{~N}_{2} \mathrm{BrO}_{2}\right]^{+}} \\
278(5.30) \\
\\
{\left[\mathrm{C}_{10} \mathrm{H}_{7} \mathrm{NBrO}^{+}{ }^{+}\right.} \\
236(3.80) \\
\\
{\left[\mathrm{C}_{9} \mathrm{H}_{7} \mathrm{BrO}^{+}{ }^{+}\right.} \\
210(18.50) \\
\\
{\left[\mathrm{C}_{9} \mathrm{H}_{6} \mathrm{O}\right]^{+}} \\
130(16.70) \\
\\
{\left[\mathrm{C}_{8} \mathrm{H}_{6} \mathrm{O}\right]^{+}} \\
100(18.90) \\
\\
{\left[\mathrm{C}_{6} \mathrm{H}_{2}\right]^{++}} \\
74(27.80)\end{array}$ & $\begin{array}{c}\left.\text { 339( } \mathrm{M}^{+}+2,100\right), 338\left(\mathrm{M}^{+}+1,\right. \\
53.20), 336\left(\mathrm{M}^{+}-1,68.20\right), \\
299(4.40), 297(3.10), \\
296(3.50), 281(6.60), \\
279(10.60), 266(26.40), \\
265(13.70), 264(20.70), \\
263(15.20), 258(82.40), \\
257(69.60), 255(60.80), \\
253(13.20), 231(16.30), \\
230(15.00), 224(11.909), \\
222(12.80), 216(22.50), \\
214(78.90), 2143(50.20), \\
212(62.10), 201(70.00), \\
200(44.10), 199(69.20), \\
198(52.00), 187(10.60), \\
186(18.50), 172(19.60), \\
170(15.90), 159(19.80), \\
157(20.70), 145(12.80), \\
143(23.30), 132(10.10), \\
103(20.70), 102(28.20), \\
90(23.80), 88(30.00), \\
76(44.109), 65(22.90), \\
\text { 64(31.30), 63(70.50), }\end{array}$ \\
\hline
\end{tabular}




\begin{tabular}{|c|c|c|c|c|c|c|}
\hline & & & & & & $62(42.70)$ \\
\hline 5 & $\begin{array}{c}\left.\mathrm{C}_{21} \mathrm{H}_{14} \mathrm{~N}_{3} \mathrm{BrO}_{2} \mathrm{~S}\right]^{+} \\
451(25.20)\end{array}$ & $\begin{array}{c}\mathrm{C}_{10} \mathrm{H}_{8} \mathrm{~N}_{2} \mathrm{~S} \\
\mathrm{C}_{4} \mathrm{NO} \\
\mathrm{CH}_{3} \\
\mathrm{CO} \\
\mathrm{Br}\end{array}$ & $\begin{array}{c}{\left[\mathrm{C}_{11} \mathrm{H}_{6} \mathrm{NBrO}_{2}\right]^{\cdot}} \\
263(23.20) \\
\\
{\left[\mathrm{C}_{7} \mathrm{H}_{6} \mathrm{BrO}\right]^{+}} \\
185(100.00) \\
\\
{\left[\mathrm{C}_{6} \mathrm{H}_{3} \mathrm{BrO}\right]^{+}} \\
170(14.30) \\
{\left[\mathrm{C}_{5} \mathrm{H}_{3} \mathrm{Br}\right]^{+}} \\
142(9.80) \\
{\left[\mathrm{C}_{5} \mathrm{H}_{3}\right]^{+}} \\
63(2.70)\end{array}$ & $\begin{array}{c}\mathrm{S} \\
\mathrm{CH}_{3} \\
\mathrm{C}_{2} \mathrm{H}_{2}\end{array}$ & $\begin{array}{c}\left.\mathrm{C}_{10} \mathrm{H}_{8} \mathrm{~N}_{2} \mathrm{~S}\right]^{+} \\
188(22.30) \\
\\
{\left[\mathrm{C}_{9} \mathrm{H}_{8} \mathrm{~S}\right]^{+}} \\
148(33.30) \\
\\
{\left[\mathrm{C}_{9} \mathrm{H}_{8}\right]^{+}} \\
116(17.00) \\
{\left[\mathrm{C}_{8} \mathrm{H}_{5}\right]^{+}} \\
101(10.70) \\
{\left[\mathrm{C}_{6} \mathrm{H}_{3}\right]^{+}} \\
75(12.50)\end{array}$ & $\begin{array}{c}453\left(\mathrm{M}^{+}+2,25.00\right), \\
452(28.60), 423(3.60), \\
422(7.10), 283(8.00), \\
282(6.30), 281(5.40), \\
266(25.90), 265(31.30), \\
264(27.70), 217(12.50), \\
192(7.10), 190(8.80), \\
189(22.30), 186(20.50), \\
184(70.50), 174(0.70), \\
149(10.70), 147(31.30), \\
146(23.20), 133(7.10), \\
129(13.40), 127(12.50), \\
115(12.50), 114(28.30), \\
111(10.70), 109(11.60), \\
102(10.70), 100(9.90), \\
96(13.40), 95(14.30), \\
88(11.60), 87(15.20), \\
86(11.80), 74(10.70), \\
73(19.60), 71(26.80), \\
64(23.20), 57(33.90), \\
55(33.00), 52(10.70)\end{array}$ \\
\hline 6 & $\begin{array}{c}{\left[\mathrm{C}_{14} \mathrm{H}_{11} \mathrm{~N}_{4} \mathrm{BrO}_{3}\right]^{+}} \\
362(41.20)\end{array}$ & $\begin{array}{c}\mathrm{CH}_{2} \mathrm{CO}, \\
\mathrm{NH}-\mathrm{CN} \\
\mathrm{C}_{4} \mathrm{H}_{2} \mathrm{~N}_{2} \mathrm{O} \\
\mathrm{Br} \\
\mathrm{CH}_{3} \mathrm{O}\end{array}$ & $\begin{array}{c}{\left[\mathrm{C}_{11} \mathrm{H}_{8} \mathrm{~N}_{2} \mathrm{BrO}_{2}\right]} \\
+ \\
279(70.60) \\
\\
{\left[\mathrm{C}_{7} \mathrm{H}_{6} \mathrm{BrO}\right]^{+}} \\
185(29.90) \\
\\
{\left[\mathrm{C}_{7} \mathrm{H}_{6} \mathrm{O}\right]^{+}} \\
106(47.10) \\
\\
{\left[\mathrm{C}_{6} \mathrm{H}_{3}\right]^{+}} \\
75(64.70)\end{array}$ & $\begin{array}{c}\mathrm{CH}_{2} \mathrm{CO} \\
\mathrm{NCO} \\
\mathrm{NH}-\mathrm{CN} \\
\mathrm{CN} \\
\mathrm{C}_{2} \mathrm{H}_{2} \\
\mathrm{CH}_{2} \mathrm{O}\end{array}$ & $\begin{array}{c}{\left[\mathrm{C}_{12} \mathrm{H}_{9} \mathrm{~N}_{4} \mathrm{BrO}_{2}\right]^{+}} \\
320(25.30) \\
{\left[\mathrm{C}_{11} \mathrm{H}_{9} \mathrm{~N}_{3} \mathrm{BrO}\right]^{+}} \\
320(25.30) \\
{\left[\mathrm{C}_{10} \mathrm{H}_{8} \mathrm{NBrO}^{++}\right.} \\
237(19.20) \\
{\left[\mathrm{C}_{9} \mathrm{H}_{8} \mathrm{BrO}\right]^{+}} \\
211(26.50) \\
{\left[\mathrm{C}_{7} \mathrm{H}_{6} \mathrm{BrO}\right]^{+}} \\
125(29.40) \\
{\left[\mathrm{C}_{6} \mathrm{H}_{4} \mathrm{Br}\right]^{+}} \\
155(16.20)\end{array}$ & $\begin{array}{c}364\left(\mathrm{M}^{+}+2,52.90\right), \\
363\left(\mathrm{M}^{+}+1,23.50\right), \\
298(29.60), 295(11.80), \\
294(35.30), 276(4.20), \\
275(23.50), 263(29.40), \\
260(35.30), 200(41.20), \\
186(5.90), 172(41.20), \\
171(29.60), 167(58.80), \\
151(35.30), 150(23.50), \\
149(94.10), 148(94.10), \\
128(58.80), 114(64.70), \\
113(64.40), 112(47.10), \\
104(68.80), 99(35.50), \\
98(35.50), 88(82.40), \\
80(59.9), 79(41.20), \\
73(35.80), 71(64.10), \\
70(100), 69(70.60), \\
63(35.30), 57(82.40), \\
57(82.40), 56(82.40)\end{array}$ \\
\hline 8 & $\begin{array}{c}{\left[\mathrm{C}_{15} \mathrm{H}_{11} \mathrm{~N}_{4} \mathrm{BrO}_{3}\right]^{+}} \\
374(42.20)\end{array}$ & $\begin{array}{c}\mathrm{C}_{3} \mathrm{H}_{3} \mathrm{O} \\
\mathrm{CN} \\
\mathrm{NH}_{2}, \mathrm{CO} \\
\mathrm{CH}_{2} \mathrm{O}, \mathrm{HBr} \\
\mathrm{CN} \\
\mathrm{C}_{2} \mathrm{H}_{2}\end{array}$ & $\begin{array}{c}{\left[\mathrm{C}_{12} \mathrm{H}_{8} \mathrm{~N}_{4} \mathrm{BrO}_{2}\right]} \\
+ \\
319(14.10) \\
\\
{\left[\mathrm{C}_{11} \mathrm{H}_{8} \mathrm{~N}_{3} \mathrm{BrO}_{2}\right]^{\cdot}} \\
+ \\
293(10.90) \\
\\
{\left[\mathrm{C}_{10} \mathrm{H}_{8} \mathrm{~N}_{2} \mathrm{BrO}\right]^{+}} \\
237(14.20) \\
\\
{\left[\mathrm{C}_{9} \mathrm{H}_{5} \mathrm{~N}\right]^{+}} \\
127(7.80) \\
{\left[\mathrm{C}_{8} \mathrm{H}_{5}\right]^{+}} \\
101(15.60) \\
{\left[\mathrm{C}_{6} \mathrm{H}_{3}\right]^{+}} \\
75(15.60)\end{array}$ & $\begin{array}{c}\mathrm{C}_{10} \mathrm{H}_{6} \mathrm{NBrO} \\
\mathrm{NCO} \\
\mathrm{CN}\end{array}$ & $\begin{array}{c}{\left[\mathrm{C}_{5} \mathrm{H}_{5} \mathrm{~N}_{3} \mathrm{O}_{2}\right]^{+}} \\
139(14.20) \\
\\
{\left[\mathrm{C}_{4} \mathrm{H}_{5} \mathrm{~N}_{2} \mathrm{O}_{2}\right]^{+}} \\
96(10.90) \\
\\
{\left[\mathrm{C}_{3} \mathrm{H}_{5} \mathrm{NO}\right]^{+}} \\
73(39.10)\end{array}$ & $\begin{array}{c}376\left(\mathrm{M}^{+}+2,23.4\right), \\
375\left(\mathrm{M}^{+}+1,25.00\right), \\
372(6.30), 359(10.90), \\
292(9.40), 295(12.50), \\
294(4.80), 248(7.80), \\
247(6.30), 239(7.80), \\
238(0.90), 213(7.8), \\
201(20.30), 199(17.20), \\
198(9.40), 155(10.90), \\
142(7.80), 140(10.90), \\
128(7.80), 114(17.20), \\
98(10.90), 96(10.90), \\
89(12.90), 87(14.10), \\
85(18.50), 80(4.10), \\
79(20.30), 77(18.80), \\
72(12.50), 64(12.50), \\
63(15.60), 60(50.00), \\
59(21.90), 56(26.60), \\
55(100), 54(67.20)\end{array}$ \\
\hline 9 & $\begin{array}{c}{\left[\mathrm{C}_{21} \mathrm{H}_{17} \mathrm{~N}_{4} \mathrm{BrO}_{3}\right]^{+}} \\
452(15.20)\end{array}$ & $\begin{array}{c}\mathrm{C}_{9} \mathrm{H}_{8} \mathrm{O} \\
\mathrm{NH}-\mathrm{CN} \\
\mathrm{NCO} \\
\mathrm{C}_{2} \mathrm{~N} \\
\mathrm{OCH}_{3}\end{array}$ & $\begin{array}{c}{\left[\mathrm{C}_{12} \mathrm{H}_{9} \mathrm{~N}_{4} \mathrm{BrO}_{2}\right]} \\
+ \\
320(42.50) \\
\\
{\left[\mathrm{C}_{11} \mathrm{H}_{8} \mathrm{~N}_{2} \mathrm{BrO}_{2}\right]} \\
+ \\
279(42.50) \\
\\
{\left[\mathrm{C}_{10} \mathrm{H}_{8} \mathrm{NBrO}\right]^{+}} \\
237(15.50) \\
\\
{\left[\mathrm{C}_{8} \mathrm{H}_{8} \mathrm{BrO}\right]^{+}} \\
199(30.00)\end{array}$ & $\begin{array}{c}\mathrm{CH}=\mathrm{C}=\mathrm{O} \\
\mathrm{CH}_{3}\end{array}$ & $\begin{array}{c}\left.\mathrm{C}_{9} \mathrm{H}_{8} \mathrm{O}\right]^{+} \\
132(12.20) \\
\\
{\left[\mathrm{C}_{7} \mathrm{H}_{7}\right]^{+}} \\
91(62.50) \\
\\
{\left[\mathrm{C}_{6} \mathrm{H}_{4}\right]^{+}} \\
76(25.50) \\
\\
{\left[\mathrm{C}_{4} \mathrm{H}_{2}\right]^{+}} \\
50(42.50)\end{array}$ & $\begin{array}{c}454\left(\mathrm{M}^{+}+2,13.20\right), \\
453\left(\mathrm{M}^{+}+1,6.20\right), \\
322(55.00), 321(27.50), \\
319(32.50), 280(40.00), \\
278(27.50), 235(12.20), \\
226(12.50), 201(10.00), \\
200(15.00), 168(15.00), \\
167(15.00), 161(15.00), \\
143(10.00), 142(17.50), \\
141(15.20), 129(37.50), \\
128(20.00), 119(55.50), \\
118(40.00), 115(22.50), \\
106(12.50), 105(32.50), \\
101(27.50), 100(25.00),\end{array}$ \\
\hline
\end{tabular}




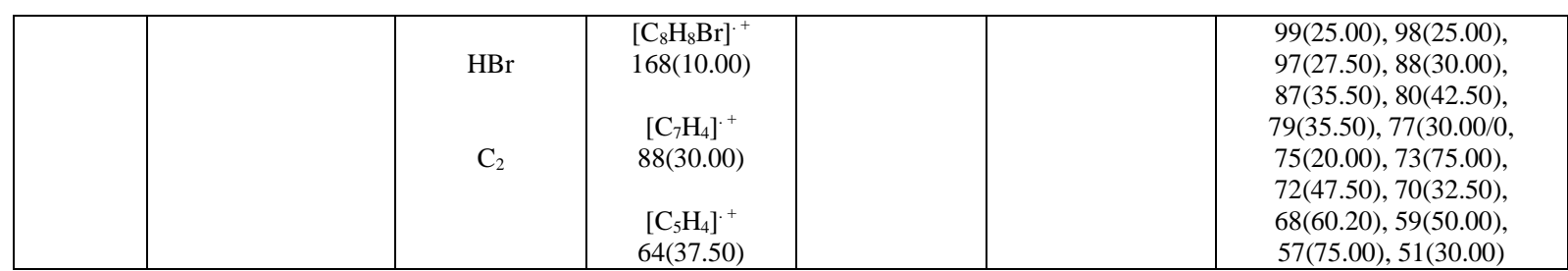

\section{1) Antimicrobial activity}

\section{Biological activity}

Using paper disc agar diffusion technique $[11,12]$ all the newly synthesized compounds were tested in vitro for antibacterial activity against sever at strains of bacteria such as Bacillus subtilis, Straphylocouus aureas, Streptococcus pneumonia, Escherichia coli and Pseudomonas solanarium. Also these compounds were tested in vitro against some fungi such as Aspergillus Nigar and Penicillium. The selectivity of compounds 3, 4, 5, 6 and 9 were tested at $100 \mu \mathrm{g} / \mathrm{ml}$ concentration and the activity was determined by measuring Zone of inhibition. The screening results given in Table 2 indicated that all the compounds exhibited antibacterial and antifungal activities against one or the other type of bacteria and fungi. From the results obtained, it is clear that compound 3 showed mild activity against the tested bacteria and fungi. Compound 4 showed high activity toward the test bacteria and moderate activity toward the tested fungi. Compounds 5 and 9 showed moderate activity against the test bacteria and high activity against the tested fungi. Compound 6 showed moderate activity towards both the test bacteria and fungi.

Table 2: Antimicrobial Activity

\begin{tabular}{|c|c|c|c|c|c|c|c|}
\hline \multirow{3}{*}{$\begin{array}{l}\text { Compd } \\
\text { No }\end{array}$} & \multicolumn{5}{|c|}{ Antibacterial Activity } & \multirow{2}{*}{\multicolumn{2}{|c|}{ Antifungal Activity }} \\
\hline & \multicolumn{3}{|c|}{ Gram Positive Bacteria } & \multicolumn{2}{|c|}{ Gram Negative Bacteria } & & \\
\hline & $\begin{array}{l}\text { Bacillus } \\
\text { Subtilis }\end{array}$ & $\begin{array}{c}\text { Staphylococcus } \\
\text { Aureas }\end{array}$ & $\begin{array}{c}\text { Streptococcus } \\
\text { Penumonia }\end{array}$ & $\begin{array}{l}\text { Escherichia } \\
\text { Coli }\end{array}$ & PesudomonasSolanarium & AspergillusNigaer & Penicillium \\
\hline 3 & + & + & + & + & - & + & + \\
\hline 4 & +++ & +++ & ++ & ++ & ++ & ++ & + \\
\hline 5 & ++ & ++ & + & +++ & +++ & +++ & +++ \\
\hline 6 & ++ & + & +++ & ++ & ++ & ++ & ++ \\
\hline 9 & + & ++ & ++ & +++ & ++ & +++ & +++ \\
\hline
\end{tabular}

- No antimicrobial activity, + Mild activity, ++ Moderate activity, +++ Marked activity

\section{2) Anticancer evaluation}

The cytotoxicity and antitumor activity of the prepared compounds 3, 4, 5 and 6 wereevaluated of cytotoxicity against MCF-7 cell line according to the method of Masmann [13] and Vrjayen [14]. Inhibitory activity against Breast carcinoma cells (MCF-7 cell line) was detected by using different concentrations of the tested compounds from $(0-50 \mu g)$ and viability \% was detected. Also, inhibitory concentration fifty $\left(I C_{50}\right)$ for compounds 3, 4, 5 and 6 were calculated from figures 7- 10 respectively. Inhibitory activity concentrations fifty $\left(I C_{50}\right)$ detected under the experimental conditions were to be $9.5 \mu \mathrm{g}$ for compound $6,10.42$ for compound $3,11.8$ $\mu g$ for compound 5 and $17.1 \mu g$ for compound 4 . These results revealed that, all the tested compounds have cytotoxic and antitumor activities against Breast carcinoma cells with superiority of the prepared compound 6 with inhibitory concentration fifty $\left(I C_{50}\right)$ equal to $9.5 \mu \mathrm{g}$. 

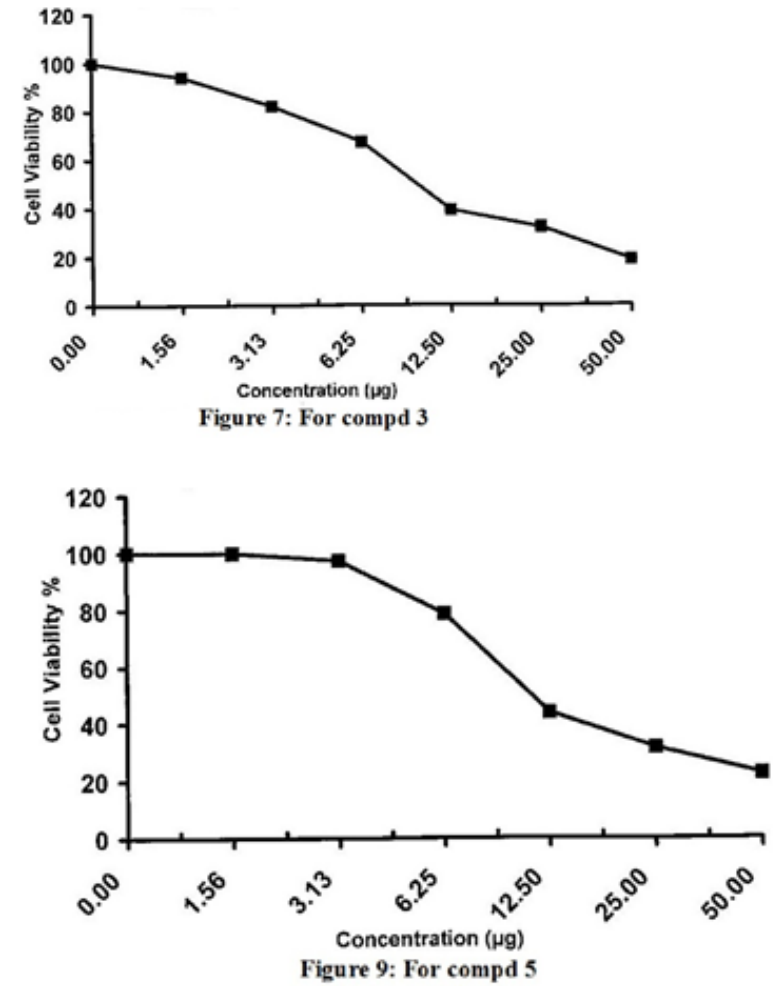
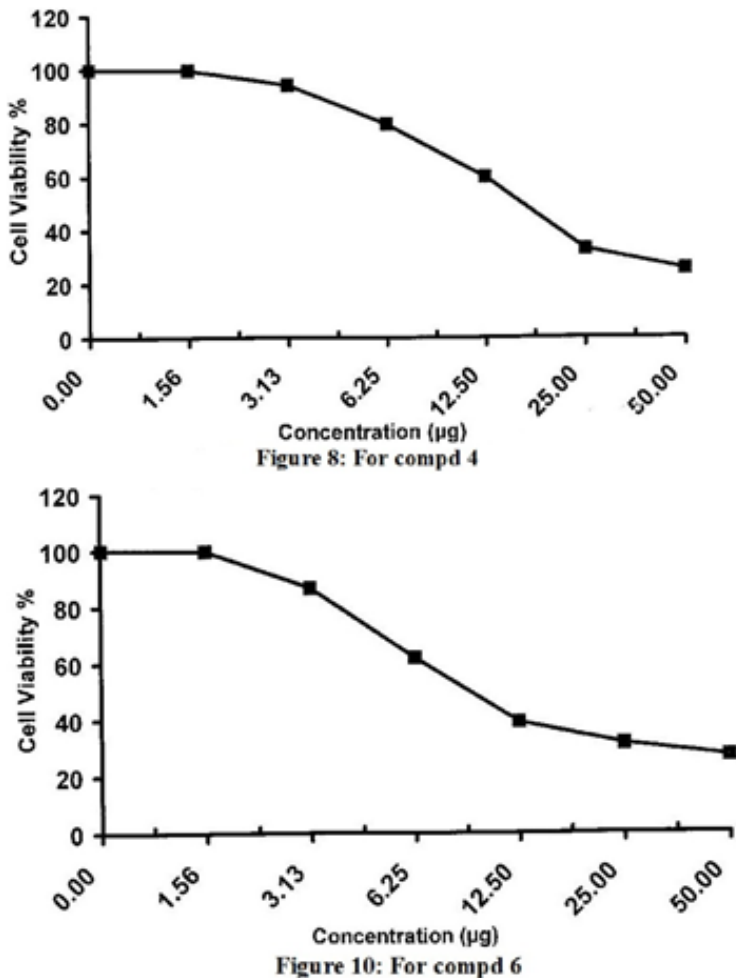

\section{Experimental}

Melting points were determined in capillaries with a Thomas-Hover Uni-Melt apparatus and are uncorrected. Infrared spectra were taken on a Perkin-Elmer 1420 spectrometer and a Biorad FTS7 (KBr). Proton NMR spectra were recorded on a general electric QE 300 instrument and chemical shifts are given with respect to TMS. Mass spectra were recorded on a Jeol JMS D-300 spectrometer operating at $70 \mathrm{eV}$. Microanalyses were conducted using an elemental analyzer 1106.

Ethyl- $\beta$-(3-bromo-4-methoxyphenyl)- $\alpha$-cyanoacrylate (2)

A mixture of 3-bromo-4-methoxybenzaldehyde $(0.01 \mathrm{~mole})$, ethyl cyanoacetate $(0.01 \mathrm{~mole})$ and anhydrous potassium carbonate $(0.03$ mole $)$ in methanol $(50 \mathrm{ml})$ was heated under reflux for $2 \mathrm{hrs}$, then cooled and poured into water. The resulting solid was filtered off, washed with water, dried and purified with ethanol to give 2 as colorless crystals, yield 87\%, mp: $130^{\circ} \mathrm{C}, \mathrm{IR}(\mathrm{KBr}): 2225(\mathrm{CN}), 1748(\mathrm{C}=\mathrm{O}), 1589(\mathrm{C}=\mathrm{C}), 1215,1078(\mathrm{C}-\mathrm{O}) \mathrm{cm}^{-}$ ${ }^{1} .{ }^{1} \mathrm{H}-\mathrm{NMR}\left(\mathrm{DMSO}-\mathrm{d}_{6}\right): \delta 1.3\left(\mathrm{t}, 3 \mathrm{H}, \mathrm{CH}_{3}\right), 3.85\left(\mathrm{~s}, 3 \mathrm{H}, \mathrm{OCH}_{3}\right), 4.36\left(\mathrm{q}, 2 \mathrm{H}, \mathrm{OCH}_{2}\right) 6.98-7.71(\mathrm{~m}, 4 \mathrm{H}, \mathrm{Ar}-\mathrm{H}$ and H-olefinic) ppm. Anal. Found: C, 50.37; H, 3.66; N, 4.46. $\mathrm{C}_{13} \mathrm{H}_{12} \mathrm{NBrO}_{3}$ requires: C, 50.48; H, 3.88; N, 4.53.

6-(3-Bromo-4-methoxyphenyl)-5-cyano-4-hydroxy-2-substituted-pyrimidines (3 and 4)

A mixture of 2 (0.01 mole), guanidine hydrochloride or thiourea $(0.01 \mathrm{~mole})$ in methanol $(50 \mathrm{ml})$ in presence of anhydrous potassium carbonate $(0.03$ mole) was heated under reflux for $4 \mathrm{hrs}$, then cooled and poured into icedilute hydrochloric acid $(1 \mathrm{~N})$. The resulting solid was filtered off, washed with water, dried and purified by recrystallization from suitable solvent to give 3 and 4.

6-(3-Bromo-4-methoxyphenyl)-5-cyano-4-hydroxy-2-amino-pyrimidine(3) as pale yellow crystals, yield 63\%, mp: $320^{\circ} \mathrm{C}$, IR(KBr): 3351, $3158\left(\mathrm{NH}_{2}\right), 3398-2850$ (br. $\left.\mathrm{OH}\right), 2223(\mathrm{CN}), 1625(\mathrm{C}=\mathrm{N}), 1608,1581(\mathrm{C}=\mathrm{C})$, $1251,1083(\mathrm{C}-\mathrm{O}) \mathrm{cm}^{-1} .{ }^{1} \mathrm{H}-\mathrm{NMR}\left(\mathrm{DMSO}_{6}\right): \delta 3.88\left(\mathrm{~s}, 3 \mathrm{H}, \mathrm{OCH}_{3}\right), 7.40-7.91(\mathrm{~m}, 3 \mathrm{H}, \mathrm{Ar}-\mathrm{H}), 8.50\left(\mathrm{~s}, 2 \mathrm{H}, \mathrm{NH}_{2}\right)$, 10.98 (s, 1H, OH) ppm. Anal. Found: C, 44.91; H, 2.68; N, 17.35. $\mathrm{C}_{12} \mathrm{H}_{9} \mathrm{~N}_{4} \mathrm{BrO}_{2}$ requires: C, 45.00; $\mathrm{H}, 2.81 ; \mathrm{N}$, 17.50 .

6-(3-Bromo-4-methoxyphenyl)-5-cyano-4-hydroxy-2-mercapto--pyrimidine(4) as pale yellow crystals, yield 67\%, mp: $220^{\circ} \mathrm{C}, \mathrm{IR}(\mathrm{KBr}): 3389-2850$ (br. OH), $2227(\mathrm{CN}), 1628(\mathrm{C}=\mathrm{N}), 1608,1589(\mathrm{C}=\mathrm{C}), 1213,1121,1083$ (C-O) $\mathrm{cm}^{-1} .{ }^{1} \mathrm{H}-\mathrm{NMR}\left(\mathrm{DMSO}_{6}\right): \delta 3.89\left(\mathrm{~s}, 3 \mathrm{H}, \mathrm{OCH}_{3}\right), 7.31-7.81(\mathrm{~m}, 3 \mathrm{H}, \mathrm{Ar}-\mathrm{H}), 9.21(\mathrm{~s}, 1 \mathrm{H}, \mathrm{SH}), 10.83(\mathrm{~s}, 1 \mathrm{H}$, $\mathrm{OH}$ ) ppm. Anal. Found: C, 42.57; H, 2.26; N, 12.33; S, 9.28. $\mathrm{C}_{12} \mathrm{H}_{9} \mathrm{~N}_{4} \mathrm{BrO}_{2}$ requires: C, 42.73; H, 2.37; N, 17.46; S, 9.49 . 
6-(3-Bromo-4-methoxyphenyl)-5-cyano-3-( $p$-tolyl)-thiazolo-[3,2-b]-pyrimidin-4-one (5)

A mixture of $4(0.01$ mole $)$ and 4-methyl phenacylbromide $(0.01$ mole $)$ in acetic acid $(30 \mathrm{ml})$ in presence of fused sodium acetate $(0.03$ mole) was heated under reflux for $4 \mathrm{hrs}$, then cooled and poured into water. The crude product obtained was filtered off, washed with water, dried and purified by recrystallization from ethanol to give 5 as a yellow crystals, yield $71 \%, \mathrm{mp}: 170^{\circ} \mathrm{C}, \mathrm{IR}(\mathrm{KBr}): 2225(\mathrm{CN}), 1695(\mathrm{C}=\mathrm{O}), 1627(\mathrm{C}=\mathrm{N}), 1606$, $1588(\mathrm{C}=\mathrm{C}), 1271,1075(\mathrm{C}-\mathrm{O}) \mathrm{cm}^{-1} .{ }^{1} \mathrm{H}-\mathrm{NMR}\left(\mathrm{DMSO}_{6}\right): \delta 2.23\left(\mathrm{~s}, 3 \mathrm{H}, \mathrm{CH}_{3}\right), 3.88\left(\mathrm{~s}, 1 \mathrm{H}, \mathrm{COCH}_{3}\right), 7.12-7.89$ $\left(\mathrm{m}, 8 \mathrm{H}, \mathrm{Ar}-\mathrm{H}\right.$ and thiazole) ppm. Anal. Found: $\mathrm{C}, 55.71 ; \mathrm{H}, 2.98 ; \mathrm{N}, 9.11 ; \mathrm{S}, 7.02 . \mathrm{C}_{21} \mathrm{H}_{14} \mathrm{~N}_{3} \mathrm{BrO}_{2} \mathrm{~S}$ requires: $\mathrm{C}$, 55.88; H, 3.10; N, 9.31; S, 7.09.

6-(3-Bromo-4-methoxyphenyl)-5-cyano-3-hydroxy-2-acetylamino)-pyrimidine (6)

A solution of $3(0.01 \mathrm{~mole})$ in acetic anhydride $(20 \mathrm{ml})$ was refluxed for $2 \mathrm{hrs}$., then cooled and poured into icewater. The solid obtained was filtered off, washed with water, dried and purified by ethanol to give 6 as pale yellow crystals, yield $56 \%$, mp: $245^{\circ} \mathrm{C}$. IR( $\left.\mathrm{KBr}\right)$ : 3341-2450 (br. $\left.\mathrm{OH}\right), 3212(\mathrm{NH}), 2225(\mathrm{CN}), 1605,1589$ $(\mathrm{C}=\mathrm{C}), 1212,1083(\mathrm{C}-\mathrm{O}) \mathrm{cm}^{-1} .{ }^{1} \mathrm{H}-\mathrm{NMR}\left(\mathrm{DMSO}_{\mathrm{d}}\right): \delta 2.25\left(\mathrm{~s}, 3 \mathrm{H}, \mathrm{COCH}_{3}\right), 3.89\left(\mathrm{~s}, 3 \mathrm{H}, \mathrm{OCH}_{3}\right), 7.32-7.68$ $(\mathrm{m}, 3 \mathrm{H}, \mathrm{Ar}-\mathrm{H}), 10.20(\mathrm{~s}, 1 \mathrm{H}, \mathrm{NH}), 11.20(\mathrm{~s}, 1 \mathrm{H}, \mathrm{OH}) \mathrm{ppm}$. Anal. Found: C, 46.23; H, 3.01; N, 15.47. $\mathrm{C}_{14} \mathrm{H}_{11} \mathrm{~N}_{4} \mathrm{BrO}_{3}$ requires: $\mathrm{C}, 46.41 ; \mathrm{H}, 3.04 ; \mathrm{N}, 15.47$.

\section{6-Hydroxy-5-cyano-4-(3-bromo-4-methoxyphenyl)-imidazolidino-[2,1-b]-pyrimidin-3-one (7)}

A mixture of $3(0.01$ mole $)$ and ethyl chloroacetate $(0.01$ mole $)$ and fused sodium acetate $(0.03$ mole $)$ in acetic acid $(30 \mathrm{ml})$ was heated under reflux for $4 \mathrm{hrs}$, then cooled and poured into ice-water. The crude product obtained was filtered off, washed with water, dried and purified by recrystallization from ethanol to give 7 as a yellow crystals, yield $62 \%, \mathrm{mp}: 260^{\circ} \mathrm{C}, \mathrm{IR}(\mathrm{KBr}): 3396-2850(\mathrm{br} . \mathrm{OH}), 2226(\mathrm{CN}), 1698(\mathrm{C}=\mathrm{O}), 1629(\mathrm{C}=\mathrm{N})$, $1608,1591(\mathrm{C}=\mathrm{C}), 1263,1075(\mathrm{C}-\mathrm{O}) \mathrm{cm}^{-1} .{ }^{1} \mathrm{H}-\mathrm{NMR}$ (DMSO-d $\left.\mathrm{d}_{6}\right): \delta 3.88\left(\mathrm{~s}, 3 \mathrm{H}, \mathrm{OCH}_{3}\right), 4.25\left(\mathrm{~s}, 2 \mathrm{H}, \mathrm{NCH}_{2} \mathrm{CO}\right)$, 7.31- $7.71(\mathrm{~m}, 3 \mathrm{H}, \mathrm{Ar}-\mathrm{H}), 11.21(\mathrm{~s}, 1 \mathrm{H}, \mathrm{OH}) \mathrm{ppm}$. Anal. Found: C, 46.46; H, 2.33; N, 15.36. $\mathrm{C}_{14} \mathrm{H}_{9} \mathrm{~N}_{4} \mathrm{BrO}_{3}$ requires: $\mathrm{C}, 46.67 ; \mathrm{H}, 2.50 ; \mathrm{N}, 15.55$.

7-Hydroxy-6-cyano-5-(3-bromo-4-methoxyphenyl)-2,3-dihydropyrimidino[2,1-b]-pyrimidin-4-one (8)

A mixture of $3(0.01 \mathrm{~mole})$, methyl acrylate $(0.01 \mathrm{~mole})$ and fused sodium acetate $(0.03$ mole $)$ in dimethylformamide $(25 \mathrm{ml})$ was refluxed for $6 \mathrm{hrs}$, then cooled and poured into ice-water. The resulting solid was filtered off, washed with water, dried and purified by recrystallization from acetic acid to give 8 as a colorless crystals, yield 62\%, mp: $290^{\circ} \mathrm{C}, \mathrm{IR}(\mathrm{KBr}): 3385-2920(\mathrm{br} . \mathrm{OH}), 2221(\mathrm{CN}), 1701(\mathrm{C}=\mathrm{O}), 1629(\mathrm{C}=\mathrm{N})$, 1608, $1587(\mathrm{C}=\mathrm{C}), 1218,1120,1083(\mathrm{C}-\mathrm{O}) \mathrm{cm}^{-1} .{ }^{1} \mathrm{H}-\mathrm{NMR}\left(\mathrm{DMSO}_{6}\right): \delta 2.65\left(\mathrm{t}, 2 \mathrm{H}, \mathrm{OCH}_{2}\right), 3.25(\mathrm{t}, 2 \mathrm{H}$, $\left.\mathrm{NCH}_{2}\right), 3.89\left(\mathrm{~s}, 3 \mathrm{H}, \mathrm{OCH}_{3}\right), 7.31-7.68$ (m, 3H, Ar-H), 11.21 (s, $\left.1 \mathrm{H}, \mathrm{OH}\right)$ ppm. Anal. Found: C, 48.02; H, 2.81; $\mathrm{N}$, 14.74. $\mathrm{C}_{15} \mathrm{H}_{11} \mathrm{~N}_{4} \mathrm{BrO}_{3}$ requires: $\mathrm{C}, 46.13 ; \mathrm{H}, 2.94 ; \mathrm{N}, 14.97$.

\section{2-(P-methylbenzoyl)methylamino-5-cyano-6-(3-bromo-4-methoxyphenyl)-4-hydroxy-pyrimidine (9)}

A mixture of 3 (0.01 mole) and 4-methyl-phenylacylbromide $(0.01 \mathrm{~mole})$ in acetic acid $(25 \mathrm{ml})$ was refluxed for $2 \mathrm{hrs}$, then cooled and poured into ice-water. The solid formed was filtered off, washed with water, dried and purified by recrystallization from ethanol to give 9 as a yellow crystals, yield $67 \%, \mathrm{mp}: 300^{\circ} \mathrm{C}$, $\mathrm{IR}(\mathrm{KBr})$ : 3381 2910 (br. OH), $2225(\mathrm{CN}), 1703(\mathrm{C}=\mathrm{O}), 1625(\mathrm{C}=\mathrm{N}), 1605,1583(\mathrm{C}=\mathrm{C}), 1212,1085(\mathrm{C}-\mathrm{O}) \mathrm{cm}^{-1} .{ }^{1} \mathrm{H}-\mathrm{NMR}$ (DMSO-d $\left.)_{6}\right): \delta 2.31\left(\mathrm{~s}, 2 \mathrm{H}, \mathrm{CH}_{3}\right), 3.31\left(\mathrm{~s}, 2 \mathrm{H}, \mathrm{NCH}_{2} \mathrm{CO}\right), 3.89\left(\mathrm{~s}, 3 \mathrm{H}, \mathrm{OCH}_{3}\right), 7.12-7.81(\mathrm{~m}, 7 \mathrm{H}, \mathrm{Ar}-\mathrm{H}), 11.02(\mathrm{~s}$, $1 \mathrm{H}, \mathrm{OH}) \mathrm{ppm}$. Anal. Found: $\mathrm{C}, 55.57 ; \mathrm{H}, 3.62 ; \mathrm{N}, 12.18 . \mathrm{C}_{21} \mathrm{H}_{17} \mathrm{~N}_{4} \mathrm{BrO}_{3}$ requires: $\mathrm{C}, 55.75 ; \mathrm{H}, 3.76 ; \mathrm{N}, 12.39$.

\section{References}

11] Takashi, O; Yasuhisa, K; Hiroshi, N.; PCT Int. Pat. Appl.; Chem. Abstr., 2002, 137, 154943.

[2] Baraldi, P. G.; U.S. Pat., (2002), 11, US6358964, Chem. Abstr., 2002,136, 247601

[3] Noriko, M.; Masueyuki, K.; Yuichi, T.; Toshiya, T.; Takayki, I. and Koh, T.; Pet-Pat. Appl., 2000, 136; WO2000034278 (Chem. Abstr., 2000, 133, 43529.

[4] Jain, R.; Pandey, P.; J. Indian Chem. Soc., 1988, 65, 354

[5] Mohamed, S. M.; Unis, M.; Abd El-Hady, H.; Egypt. J. Chem., 2006, 49(2), 209.

[6] El-Deen, I. M; Ibrahim, H. K.; Phosphorous, Sulfur and Silicon, 2000, 160, 241.

[7] El-Dean, I.M.; Chinese J. Chem., 1999, 17 (4), 391.

[8] Mohamed, S. M.; Bull. Chem. Technol. Macedonia, 2005, 24 (2), 117.

[9] El-Deen, I. M.; Abd El-Fattah, M. E.; Bull.Korean Chem. Soc., 2003, 24 (4), 473.

[10] Hasanen, J. A.; Egypt. J. Chem., 2007, 50 (32), 203.

[11] Cooper, K. E.; Kavanagh, E. E.; Analytical Microbiology, Vol. 2 (Academic Press, New York), 1972, pp 13.

[12] Betina, V.; The chemistry and biology of antibiotics (Edl) with natura RF Rekker, Cezhosolovakia (Elsevier Scientific Publising, New York, 1983.

[13] Mosmann, T.; Rapid colorimetric assay for cellular growth and survival: application of proliferation and cytotxicity assays; $J$. Immunol. Methods; 1983, 65, 55-63.

[14] Vijayan, P.; Raghu, C.; Asho;, G.; Dhanaraj, S.A.; Suresh, B.; Antiviral activity of medicinal plants of Nilgiris; Indian J. Med. Res.; 2004, 120, 24-29. 